(-) Elevier/North-Holland Biomedical Preas, Amsterdam - Printed in The Netherlands

\title{
THE NUCLDOTIDE SEQUENCE OF THE RIGHT-HAND TERMINUS OF ADENOVIRUS TYPE 5 DNA: IMPLICATIONS FOR THE MECHANISM OF DNA RTPLICATION
}

(DNA sequence; Maxam-Gilbert technique; replication of linear DNA; origin of Ad5 DNA replication)

\section{P.H. STEENBERG:J and J.8. SUSBENBACH}

Laboratory for Physiological Chemistry, State University of Utrecht, Utrecht (The Netherlande)

(Receined February 28th, 1979)

(Accepted April 30th, 1979)

\section{SUMMARY}

The nucleotide sequence of the right-hand terminal 3\% of adenovirus type 5 (Ad5) DNA has been determined, using the chemical degradation technique developed by Maxam and Gilbert (1977). This region of the genome comprises the 1003 basepair long HindIII-I fragment and the first 75 nucleotides of the adjacent HindIII-F fragment, extending from the righthand terminus to the sequences from which the main body of the mRNA of early region 4 is transcribed.

One of the origins of adenovirus DNA replication is located within this part of the genome. The sequencing results are discussed in relation to several models proposed for the mechanism of replication of linear DNA molecules, which invariably depend on the presence of specific arrangements of nucleotides at the termini of those linear DNAs.

\section{INTRODUCTION}

The mechanism of replication of the linear double-stranded adenovirus DNA has been the subject of extensive investigations [reviewed by Levine et al. (1976) and Winnacker (1978)]. Biochemical and electron microscopical experiments indicated that replication proceeds via a displacement mechanism (Sussenbach et al., 19. 2; Van der Eb, 1973; Tolun and Pettersson, 1975; Schilling et al., 1975; Horwitz, 1976; Weingärtner et al., 1976; Sussenbach and Kuijk, 1977; 1978). Replication starts at either end of the linear double-stranded DNA and proceeds displacing one of the parental strands. The displaced strand is later replicated in the opposite direction. All types of replicative intermediates have a linear structure.

One of the major gaps in our knowledge of adenovirus DNA replication is the mechanism by which the 5 'ends of the linear duplex are replicated. In a number of linear DNA molecules (e.g. lambda and T7 DNA) perfect terminal 
repetitions are present, allowing the formation of circular or concatemeric replicative intermediates. Based on the structure of these intermediates, several models for the initiation of DNA replication of these DNAs have been proposed (Watson, 1972). However, adeuovirus DNA possesses an inverted terminal repetition, which prohibits circularization or concatemerization of the double-stranded DNA.

A model for the replication of the 5 -ends of linear chromosomes avoiding circularization or concatemerization has been proposed by Cavalier-Smith (1974). According to this model, a self-complementary hairpin-loop at the 3 'end of the DNA provides a 3 '-OH group suitable for priming of DNA synthesis. Subsequently, the parental strand is nicked at a specific site opposite the original $3^{\prime}$-terminus which is now part of the progeny strand. The $3^{\prime}-\mathrm{OH}$ at the nick provides a primer for DNA polymerase to copy the sequences present in the hairpin structure. The original 3 '-terminal structure of the parental strand thus becomes, in an inverted form, the $5^{\prime}$ end of the progeny strand. If the nucleotide sequence involved in the initial formation of the loop-back structure is not a perfect palindrome, the model predicts the existence of two classes of progeny DNA molecules, one for each orientation of the $3^{\prime}$-terminal sequence, which moves from the parental to the progeny strand. It has been shown that the structure of adenovirus-associated virus DNA is consistent with this model (Berns et al., 1978). Intermediates with a terminal hairpin structure have also been observed during replication of the autonomous parvoviruses (Bourguignon et al., 1976; Tattersall and Ward, 1976).

An analogous mechanism has been proposed for the replication of adenovirus DNA (Wu et al., 1977). The presence of special arrangements of nucleotides at the termini of Ad2 DNA has been suggested by the electron microscopical observation of some type of secondary structure at the molecular ends. The number of nucleotides involved in this structure is estimated to be bet. ween 50 and 100 at each end. The resolution of the methods used, however, is insufficient to determine the exact nature of the observed structures, which seem to involve base pairing as in a tRNA clover leaf, rather than a single hairpin-type inverted repeat (Wu et al., 1977). Furthermore, palindromic sequences have been reported to be present in Ad2 DNA at about 180 nucleotides from the molecular ends (Padmanabhan et al., 1976). A different model for the replication of linear DNA molecules has been proposed by Heumann (1976). According to this model, the $\mathbf{5}^{\prime}$ ends of a linear DNA molecule are replicated by virtue of internal repeats of the terminal nucleotide sequence.

Nucleotide sequence analysis is the most direct approach to test whethct or not spacial arrangements other than the linear duplex structure can exist at the ends of adenovirus DNA. The nucleotide sequence of the first 194 basepairs at both termini of Ad5 DNA, including the 103 nucleotide long inverted terminal repetition, has already been described (Steenbergh et al.; 1977). The present report concerns the nucleotide sequence of the right-hand terminal 3\% (1078 nucleotides) of the Ad5 genome, which is the region between the right-hand terminus and the rightmost sequences known to be transcribed into viral mRNA. 


\section{MATERIAL AND METHODS}

\section{Materials}

Ad5 DNA was isolated from purified virions as described previously (Sussenbach, 1971). Restriction endonucleases $H$ haI and $H p h I$ were purified according to Roberts et al. (1976) and Kleid et al. (1976), respectively. HaeIII and Hinfl were purified according to the method described by Takanami and Kojo (1973). Restriction endonucleases HindIII, HpaII and AluI were purchased from Boehringer (Mannheim), SmaI from Biolabs (Beverly, MA), and ThaI (TacI) and TagI from BRL (Bethesda, MD) (for review see Roberts, 1978). Bacterial alkaline phosphatase (BAP-F) was from Worthington (Freehold, NJ) and T4 polynucleotide kinase from Boehringer (Mannheim). $\left[\gamma^{-32}\right.$ P] ATP (8pecific activity 2000-4000 Ci/mmol). was bought from the Radiochemical Centre (Amersham). Dimethylsulfate (98\%) was obtained from Merck-Schuchardt (München), hydrazine (95+\%) from Eastman-Kodak (Rochester, NY) and piperidine (99\%) from Baker Chemicals (Deventer). Acrylamide (99\%), bisacrylamide (ultra pure) and urea (99.5\%) were from BDH (Poole).

\section{DNA sequence analysis}

The isolation of the HindIII fragments of Ad5 DNA, the labeling of the 5'. ends of restriction enzyme fragments, and the DNA sequencing procedure, according to the method of Gilbert and Maxam (1977), have all been described previously (Steenbergh et al., 1977).

The only significant technical modification consisted of the omission of the heat-denaturation steps before and after the incubation with T4 polynucleotide kinase. This resulted in the incorporation of about $70 \%$ of the radioactivity incorporated when the denaturation steps were included. The autoradiograph of the gels in which the labeled fragments were separated, however, showed much less background when heat denaturation was omitted. The fragments were exclusively labeled at their $5^{\prime}$-ends, suggesting that random nicks in the DNA, probably causing the background after denaturation, were not labeled in this way.

\section{RESULT8}

In order to obtain specific subfragments suitable for sequence determination according to Maxam and Gilbert (1977), the Ad5 HindIII-I fragment was degraded with various restriction endonuclesses. The details of the procedure used for mapping of restriction enzyme recognition sites within the HindIII-I fragment, according to the method developed by Smith and Birnstiel (1976), has been described previously (Steenbergh et al., 1977). The physical maps of the HindIII-I fragment with restriction endonucleases AluI, HaeIII, HhaI, HinfI, HpaII, HphI, Thal and TaqI are shown in Fig. 1. As indicated by these maps, every nucleotide within the HindIII-I tragment is located within a distance of 75 nucleotides from one of the restriction enzyme recognition sites; this distance is small enough to permit accurate sequence analysis by the method used. 


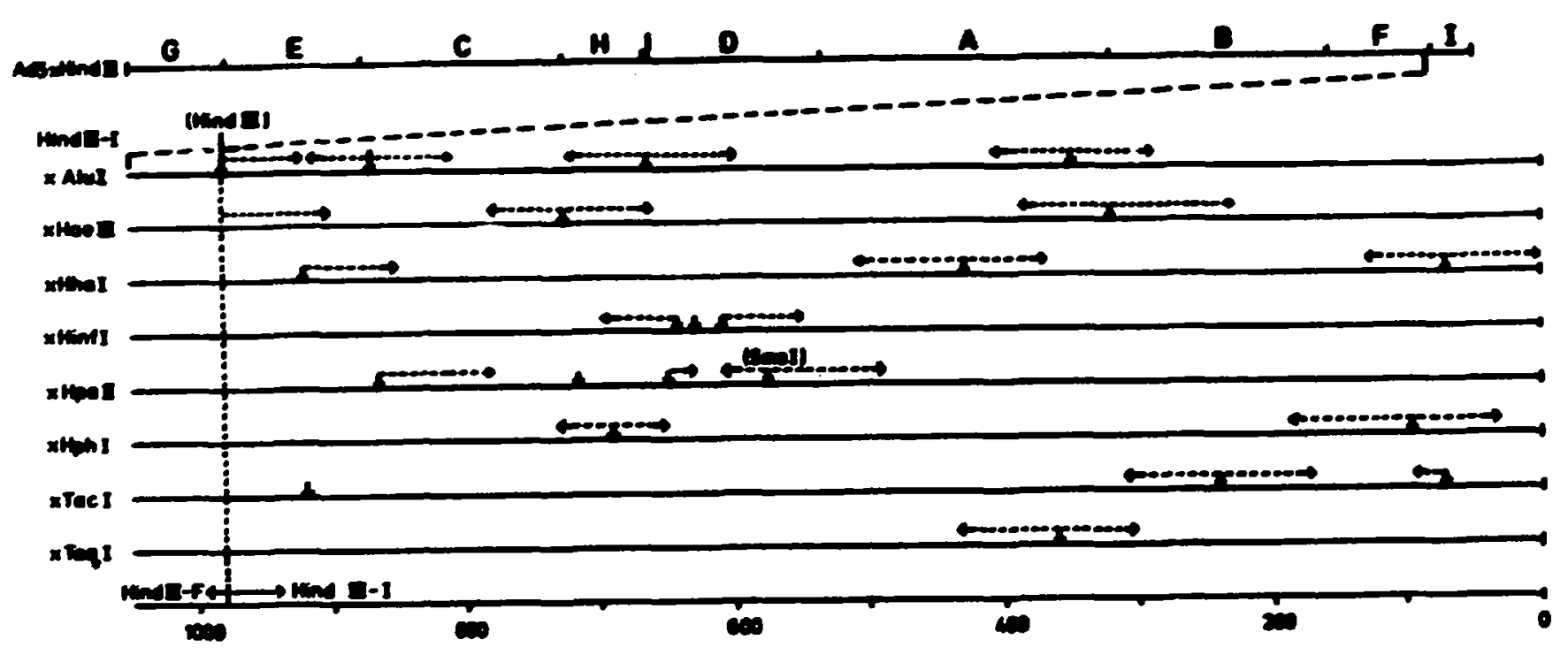

Fig. 1. Clearage mpes of the HindIII-I froment of Ad5 DNA. The arrow indicate the se quences $\left(5^{\prime} \rightarrow 8^{\prime}\right)$ which could be dexived utarting from the varions $5^{\prime}$ labeled restrietion enzy me recornition sites. The following combinations of reatriction enrymes were ued: AluI $\times$ HhaI; AluI $\times$ HoeII; HaeII $\times$ HhaI; HoeIII $\times$ AluI; HhaI $\times$ HaeIII; HhaI $\times$ HpoII; Finfl $\times$ Hhal; HpaII $\times$ HoeII; HpoII $\times$ Hinfl; HphI $\times$ HoeII; HphI $\times$ Hhal; ThaI (TocI) $\times$ HphI; TaqI $x$ Hinfl HindIII-I wes digented with the fint enzyme of a civen combination. The resulting fragments were labeled at their 5 -ends and were digented further with the rocond enzyme.

\section{DNA sequence analysis}

The HindIII-I fragment was digested separately with each of the restriction endonucleases mentioned above. The resulting tragments were labeled at their $5^{\prime}$-ends with kinase. Thus, using an enzyme which cuts the HindIII-I fragment $n$ times, $n+1$ labeled fragments were obtained. Of these fragments, $n$ were labeled at both $5^{\prime}$-ends, the fragment derived from the right-hand end of the genome being labeled at its lefthand end only, since the original terminus of Ad5 DNA is insensitive to the action of phosphatase (Carusi, 1977). Sequence analysis requires fragments which are labeled at only one $5^{\prime}$ end. In order to cleave the fragments labeled at both $5^{\prime}$-ends, the mirture of labeled fragments was further incubated with a second restriction enzyme. The combinations of restriction enzymes used arementioned in the legend of Fig. 1.

A sequence of about 80 nucleotides, starting from the labeled 5 -ends of each of the restriction enzyme fragments, could be established from the sequencing gels. Fig. 1 shows the approximate lengths of the sequences determined starting from the various restriction enzyme recognition sites.

In addition to the HindIII-I fragment, the sequence of the first 75 nucleotides of the adjacent HindIII-F fragment was analysed. The HindIII-I tragment was isolated as described for HthdIII-I. HindIII-F was labeled at both 5 ' ends with ${ }^{32} \mathrm{P}$ using polynucleotide kinase and was subsequently digested with HpaII. 
The two labeled terminal HpaII fragments (400 and about 700 nucleotides long) were separated by polyacrylamide gel electrophoresis, and subjected to sequence analysis. From double digestion experiments with SmaI and HpaII of the HindIII-F fragment, it is known that the shortest terminal HpaII fragment is located adjacent to the HindIII-I fragment (results not shown). This

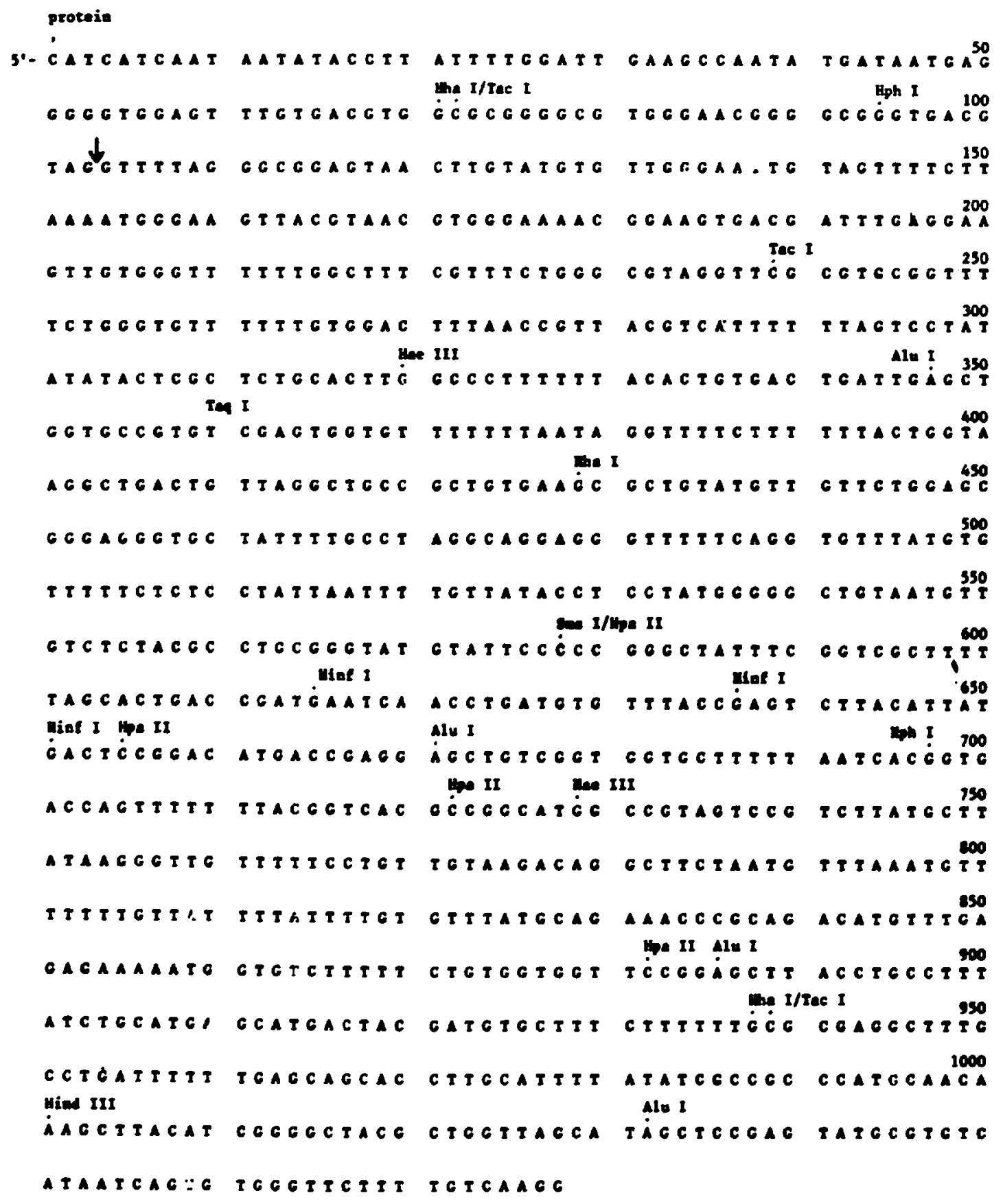

Fie. 2. Sequence of the first 1078 nucleotides at the right-hand end of Ad5 DNA in the matrand. The recopnition sites of the restriction endonucleases in Fig. 1 are indicated. The arrow at nucleotide 103 indicates the end of the inverted terminal repetition. (Restriction endonuclease Thal is indicated by the old abbreviation, TocI; Roberts, 1978). 
was confirmed by the sequencing results obtained from the longer terminal HpaII fragment of HindIII-F, which contains a $\mathrm{HpaI}$ recognition site eight nucleotides inward from the labeled HindIII site, corresponding to the Hpal-F/D junction in Ad5 DNA at map position 89.1.

Fig. 2 shows the sequence of the first 1078 nucleotides in the $r$-strand at the right-hand terminus of Ad5 DNA. As indicated in Fig. 1, about 50\% of the sequence has been established by analysis of both complementary strands. In those regions where only one strand was analysed, the sequence is based on the results of at least two independent experiments.

Some representative sequencing gels are shown in Fig. 3.

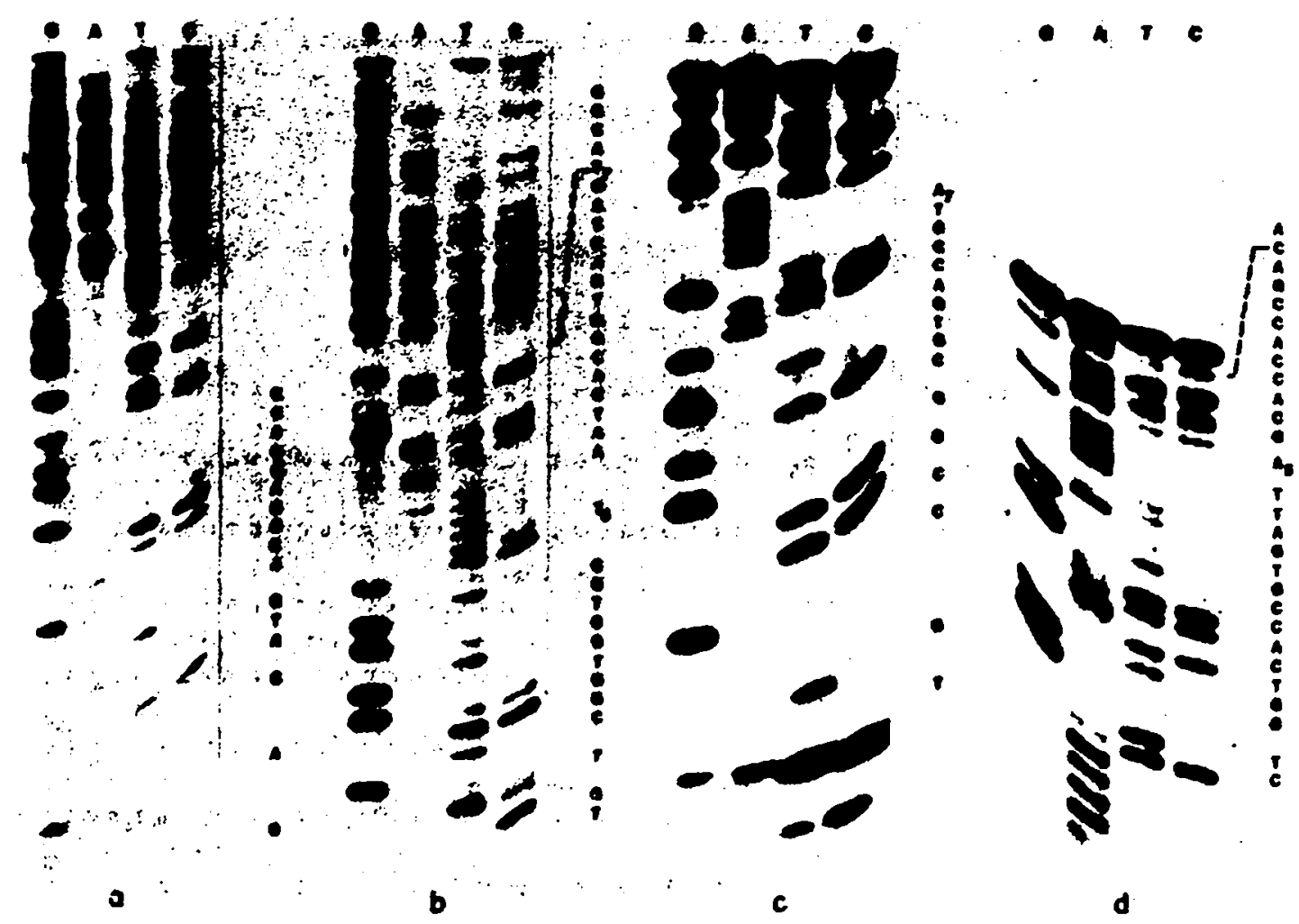

Fig. 3. Sequencing gels of a region of the HindIII-I fragment. Region between nucleotides 658 and 727 in Fig. 2. a and $b$ represent $a$ short and a long run of the HinflHhal fragment bet ween nucleotides 652 and 940 , labeled at the Hinf site in the rstrand. $c$ and $d$ are $a$ short and a long run of the HoeIII/AluI fragment between nucleotides 730 and 672, labeled at the Hae III site in the l-strand.

\section{DISCUSSION}

\section{Initiation of adenovirus DNA replication}

The primary structure of the right-hand terminal 3\% of the Ad5 genome has been determined in order to investigate whether this DNA may replicat: 
according to one of the models proposed for the mechanism of replication of linear genomes.

The $r$-strand of this region of the genome, shown in Fig. 2, is very rich in $T$ residues. Over one third of the 1078 nucleotides analysed are $T$ residues. The sequence contains 26 tracks of four or more $T$ residues, in contrast to only few $A, C$, and $G$ tracks, respectively.

Flectron microscopical analysis of partially denatured Ad5 DNA has shown that the terminal $3 \%$ of the genome exhibits high denaturability, indicating a relatively high $A+T$ content in this region (Ellens et al., 1974). This observation is confirmed by the sequence data, the overall $A+T$ content being about 55\%. Regions with $A+T$ contents of $75 \%$ or more are found between nucleotides $370-400,480-530$, and 790-830. The small region at the end of the DNA molecule with a low denaturability observed in these partial denaturation studies may be explained by the high $\mathrm{G}+\mathrm{C}$ content (75\%) of nucleotides 50 100 in the sequence.

Three palindromic arrangements of nucleotides are present within the sequence analysed, located between positions 161-170,711-736, and 10101039 in Fig. 2, respectively.

The nucleotide sequence of the terminal 3\% of the right-hand end of Ad5 DNA does not substantiate a mechanism of initiation of adenovirus DNA replication by the formation of a fold-back structure involving the 3'-end of the DNA molecule as proposed by the model of Cavalier-Smith (1974).

Since there is definitely no perfect palindrome present at the right-hand end of Ad5 DNA, the unique character of the sequence also excludes this model. For Ad2 DNA, evidence for secondary structures both within the inverted terminal repetition (Wu et al., 1977) and at about 180 nucleotides inward from the ends (Padmanabhan et al., 1976) has been obtained by electron microscopical and nuclease susceptibility studies, respectively. However, from the nucleotide sequence of the inverted terminal repetition of the closely related Ad5 DNA it is not clear how the structures within the inverted repeat are formed. On the other hand, the secondary structure observed around nucleotide 180, may be explained by the formation of the hairpin structure depicted in Fig. 4a, involving nucleotides 169-233. At the left-hand end of Ad5 DNA, a possible hairpin structure between nucleotides 156-233 in the $l$ strand has been described (Van Ormondt et al., 1978). Interestingly, stretches of 17 nucleotides with almost identical sequences (see Fig. 4b) are situated in the centre of these hypothetical hairpin structures.

Recently, several studies have been performed which resulted in a more precise localization of the origins of adenovirus DNA replication (Sussenbach and Kuijk, 1978; Ariga and Shimojo, 1978). All data presently available indicate that the origins of replication are located at, or very close to, the two molecular ends, probably within the first 260 basepairs (Winnacker. 1978). Although the sequence data exclude a hairpin-loop initiation mechanism, they do not give any indication as to the actual mechanism of initiation of DNA replication. A different model for the replication of linear chromosomes has been 
a)

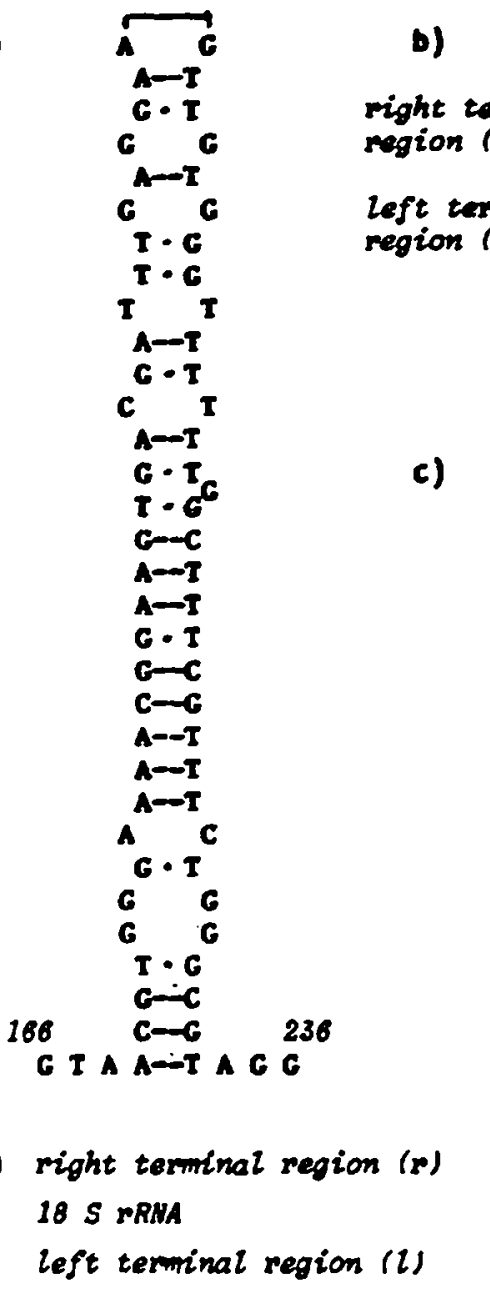

b)
179

194

5०ACGGA A G T GACGATIT-

197

212

son cag G A A G T G s. CA A T T T-

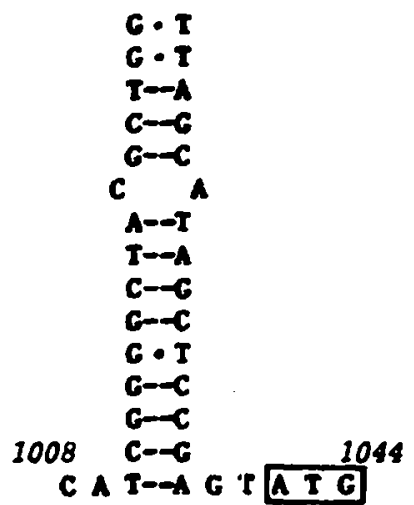

Fig. 4. (a) Region between nucleotide 169-288 in the r-strand at the right end of AdS DNA. This type of atructure may form after exonuclease III treatment of the DNA, inhibiting repair agntbeais of the l-trand by DNA polymernse I at $5^{\circ} \mathrm{C}$, a observed by Padmanab han et al. (1976) for Ad2 DNA. (b) Almont identical nucleotide wequences in both terminal regions of Ad5 DNA. The sequence from the right-hand end is part of the structure in (a), the sequence from the left-hand end is part of a similar atructure (Van Ormondt at al., 1978). (c) Pousible hairpin utructure involving nucleotides 1010-1089 of the r-atmnd at the right hand end of Ad5 DNA The boxed ATG might reprewent an initiation codon for the proteins of early region 4. (d) Comparieon of sequences in the right- and left-hand terminal resion of Ad6 DNA shortly upatrenm of posible ATG initiation codon, with the 3 -terminus of 188 ribosomal RNA. The date concerning the left-hand terminal repion have been described by Van Ormondt et al. (1978).

described by Heumann (1976). In this model, the presence of internal repeats of the terminal sequence of the DNA allows the replication of the chromosome ends. The nucleotide sequence of the right-hand terminal 3\% of Ad5 DNA does not contain a repeat of the terminal sequence which would support this type of replication mechanism.

An alternative model, proposed by Rekosh et al. (1977), suggests that the 
terminal protein acts as a primer for DNA replication. The identical 3 'ends of parental adenovirus DNA might function as recognition sites for this protein. Upon initiation of DNA replication the protein might become attached to the $5^{\prime}$-terminal nucleotide of the progeny strand, either by acting directly as a primer for the DNA polymerase or by a mechanism involving direct recognition of a nucleotide by the protein, either before or after binding to the DNA. A similar priming mechanism has been suggested to play a role in the replication of poliovirus RNA; experimental results consistent with the idea that the protein serves as a primer for synthesis of both the plus and minus strand of poliovirus RNA have been obtained (Pettersson et al., 1978).

Other possible initiation mechanisms would require the formation of circular double-stranded intermediates by joining of the molecular ends. However, covalently closed circular intermediates have never been observed in adenovirus DNA replication, and, if they occur, must be extremely short-lived.

Further studies on early replicative intermediates will have to be performed to solve the problem of initiation of adenovirus DNA replication.

\section{Transcription}

The nucleotide sequence presented in this paper is part of a region of the Ad5 genome transcribed at early times dfter infection. This region, referred to as early region 4, between 91 and 99 map units, is believed to encode at least two early proteins which have been identified in infected cells during the early phase of viral infection: an 11000 protein and a less prominent 19000 protein (Lewis et al., 1976).

Transcription of early region 4 is in the leftward direction (Sharp et al., 1974; Petterseon et al., 1976). Four transcripts have been mapped in this region of Ad2 DNA. All have their 3'end at $91 \pm 0.4$ map units (Berk and Sharp, 1977). These transcripts are $1500,1600,1900$ and 2300 nucleotides long, respectively. The 1500 nucleotide transcript is not reproducibly observed. The other three transcripts all have sequences spliced to their $5^{\prime}$-ends which map at $99.1 \pm 0.6$ map units. The length of the leader sequence(s) is estimated to be between 15 and 50 nucleotides (Berk and Sharp, 1978).

According to these data, the nucleotide sequence from which the leader sequence is transcribed is located somewhere around nucleotide 320 in the $l$ strand. Between nucleotides 300 and 306 the sequence TATATAC appears; this sequence bears a marked resemblance to presumed promoter sequences preceding the $5^{\prime}$ ends of transcripts in other eukaryotic genes (Ziff and Evans, 1978). The nucleotide sequence of the RNA would be identical to the sequence of the r-strand shown in Fig. 2. The RNA transcribed from the sequence extending to the left of this leader sequence is spliced out of the primary transcript. The main body of the 2300 nucleotide long transcript starts around position 800 in the DNA sequence (Berk and Sharp, 1978). Regions with a very high content of $G$ and $T$ residues are present close to the presumed splicing points. One region, between nucleotides 201 and 268 , is $87 \% \mathrm{G}$ and $\mathrm{T}$ and contains two tracks of $16 \mathrm{G}$ and $\mathrm{T}$ residues. A second, shorter region with 
a similarly high $\mathbf{G}+\mathbf{T}$ content is located between nucleotides 357 and 393 . Around position 800 , a region between nucleotides 751 and 820 contains $77 \%$ $G+T$, with stretches of 12 and $11 G$ and $T$ residues. Interestingly, such $G+T$ rich regions are also present in early region 1, at the left-hand of Ad5 DNA of which the nucleotide sequence has been analysed (Van Ormondt et al., 1978). Between nucleotides 1122 and 1221 , a region with $80 \% \mathrm{G}+\mathrm{T}$, containing stretches of 18 and $12 \mathrm{G}$ and $\mathrm{T}$ residues, is located close to one of the splicing points in early region 1 (Berk and Sharp, 1978). A relative abundancy of $T$ residues near splicing points has also been reported for the chick ovalbumin gene, where $T$ residues are common in the intron sequence immediately preceding an intron-ezon junction (Catterall et al., 1978).

From the fact that many nonserse codons would be present in all reading frames of RNA transcribed from either of the strands of the terminal 3\% of Ad5 DNA, it can be concluded that this region does not encode any protein products. The ATG triplet at position 1042, however, is not followed by nonsense codons within the sequence analysed. This ATG may function as the initiation codon for the 11000 or 19000 protein encoded by early region 4 . The location of this initiation codon shortly downstream from the palindromic sequence between nucleotides 1010 and 1089 (see Fig. 4c) may be significant. Directly preceding this possible initiation codon a stretch of nucleotides is present which shows complementarity with the $3^{\prime}$ end of 188 ribosomal RNA (Hagenbilchle et al., 1978) (Fig. 4d). A similar sequence is found in a number of other mRNAs. The sequence CTCCGAG (nucleotides 1034-1040) is also present in the l-strand at the left-hand end of Ad5 DNA (nucleotides 530-536) and has been suggested as a possible ribosome binding site (Van Ormondt et al., 1978).

\section{ACKNOWLEDGEMENTS}

The authors thank Dr. H.S. Jansz for critical reading of the manuscript. A generous gift of restriction endonuclease Accll by Dr. J. Arrand is gratefully acknowledged. We thank Dr. J.H. van de Pol for computer analysis of the sequence data. This investigation was supported in part by the Netherlands Foundation for Chemical Research (SON) with financial aid from the Netherlands Organisation for the Advancement of Pure Research.

\section{RBFERENCES}

Arign, H. and Shimojo, H., Initiation and termination sites of adenovirus 12 DNA replication, II. Analyris of pulse-labeled oligonucleotides derived from $5^{\prime}$ termini in the DNA strand, Virologs, 85 (1978) 98-108.

Berk, A.J. and Sharp, P.A., Ultraviolet mapping of the sdenovirus 2 early promotern. Cell, 12 (1977) 46-56.

Berk, A.J. and Sharp, P.A. Structure of the adenovirus 2 early mRNA, Cell, 14 (18'8) 685-711. 
Berns, K.I., Hauswirth, W.W., Fife, K.H. and Spear, I., In: D.C. Ward and P. Tattersall (Eds.), Replication of Mammalian Parvoviruses. Cold Spring Harbor Laboratory, Cold Spring Harbor, NY, 1978, pp. 179-192.

Bourguignon, DJ., Thattersall, P.J. and Ward, D.C., DNA of minute virus of mice: self priming, non-permuted, single stranded genome with a 5 ' terminal hairpin duplex, J. Virol., 20 (1876) 290-806.

Catterall, J.F., O'Malley, B.W., Robertson, M.A., Staden, R., Tanaka, Y. and Brownlee, G.G., Nucleotide requence homology at 12 intron-exon junctions in the chick ovalbumin gene, Nature, 275 (1978) 510-513.

Caruai, E.A., Evidence for blocked termini in human adenovirus DNA, Virology, 76 (1977) 380-394.

Cavalier-8mith, T., Palindromic base sequences and replication of eukaryotic chromosome ends, Nature, 250 (1974) 467-470.

Ellens, D.J., Sureenbach, J.S. and Jansz, H.S., Studies on the mechanism of replication of adenovirus DNA, III. Electron microscopy of replicating DNA, Virology, 61 (1974) 427-442.

Hegenbiichle, O., Santer, M. and Steitz, J.A., Conservation of the primary structure at the 3 'ends of $18 S$ rRNA from eukaryotic cells, Cell, 13 (1978) 551-563.

Heumann, J.M., A model for replication of the ends of linear chromosomes, Nucl. Acids Rea, 3 (1976) 3167-3171.

Horwitz, M.S., Bidirectional replication of adenovirus type 2 DNA, J. Virol., 18 (1976) 307-315.

Klejd, D., Hamayun, Z., Jeffrey, A. and Ptashne, A., Novel properties of a restriction endonuclease inolated from Haemophilus parahaemolyticus, Proc. Natl. Acad. Sci. USA, 73 (1876) 293-297.

Levine, AJ., Van der Viet, P.C. and Suscenbach, J.S., The replication of papovavirus and adenovirus DNA, Curr. Topics Microbiol. Immunol., 73 (1976) 67-124.

Lewis, J.B., Atkin, J.F., Buum, P.R., Solem, R., Gesteland, R.F. and Anderson, C.W., Location and identification of the genes for adenovirus type 2 early polypeptides, Cell, 7 (1976) 141-151.

Maram, A.M. and Gilbert, W., A new method for sequencing DNA, Proc. Natl. Acad. Sci. U8A, 74 (1877) 660-564.

Padmanabhan, R., Padmanabhan, R.V. and Green, M., Evidence for palindromic sequences near the termini of adenovirus 2 DNA, Biochem. Biophys. Res. Commun., 69 (1976) $860-867$.

Petteracon, R.F., Ambros, V. and Baltimore, D., Identification of a protein linked to mascent polioviru RNA and to the polyuridylic acid of negative-strand RNA, J. Virol., 27 (1878) 357-865.

Pettersson, U., Tibbetts, C. and Philipeon, L., Hybridization maps of early and late mRNA sequences on the adenovirus type 2 genome, J. Mol. Biol., 101 (1976) 479-502.

Rekosh, D.M.K., Ruseell, W.C., Bellett, A.J.D. and Robinson, A.J., Identification of a protein linked to the ends of adenovirus DNA, Cell, 11 (1977) 283-295.

Roberts, R.J., Restriction and modification enzymes and their recognition sequences, Gene, 4 (1978) 183-183.

Roberts, R.J., Meyem, P.A., Morrison, A. and Murray, K., A specific endonuclease from Haemophilus haemolyticus, J. Mol. Biol., 103 (1976) 199-208.

Schilling, R., Weing̈̈rtner, B. and Winnacker, E.L., Adenovirus type 2 DNA replication, II. Termini of DNA replication, J. Virol., 16 (1975) 767-774.

Sharp, P.A., Gallimore, P.H. and Flint, S.J., Mapping of adenovirus 2 RNA sequences in lytically infected cells and transformed cell lines, Cold Spring Harbor Symp. Quant. Biol., 39 (197 4) 457-474.

Smith, H.O. and Birnetiel, M.L., A simple method for DNA restriction site mapping, Nucl. Acids Res., 3 (1976) 2387-2898.

Steenbergh, P.H., Ment, J., Van Ormondt, H. and Sussenbach, J.S., The nucleotide sequence at the termini of adenovirus type 5 D:Fi, iviel. Acids Res., 4 (1977) 4371-4389. 
Sumenbach, J.S., On the fate of adenovirus DNA in KB cella, Virology, 46 (1871) 969-972.

Suanenbech, J.8., Van de Vliet, P.C., Ellens, D.J. and Janx, H.8., Linear intermediates in the replication of adenovirus DNA, Nature New Biol., 239 (1972) 47-49.

Sumenbech, J.S. and Kuijk, M.G., Studies on the mechanimen of replication of adenovirus DNA, V. The location of the termini of replication, Virology, 77 (1977) 149-157.

Suswenbach, J.S. and Kuijk, M.G., The mechaniam of replication of adenopirus DNA, VI. Localization of the oripins of diplecement gyntheris, Virology, 84 (1978) $609-617$.

Tulanami, M. and Kojo, H., Clenveze cite specificity of an endonuclease prepared from Hoemophilus infuenzee strain H-1, FEBS Lett., 29 (1978) 267-270.

Thtterall, P.J. and Wand, D.C., The rolling hairpin: a model for the replication of parvovirus and linesr chromosomal DNA, Nature, 263 (1976) 106-109.

Tolun, A and Pettesecon, U., Termination site for adenovirus type 2 DNA replication, J. Virol., 16 (1975) 759-766.

Van der Bb, AJ., Intermediates in type 5 adenovirus DNA replication, Virology, 61 (1973) 11-23.

Van Ormondt, H., Maat, J., de Waard, A. and Vari der Eb, A.J., The nucleotide sequence of the tranforming HpaI-E fragment of adenovirus type 5 DNA, Gene, 4 (1979) 809328.

Wateon, J.D., Origin of concatemeric T7 DNA, Nature New Biol., 239 (1972) 197-201.

Weingërtner, B., Winnacker, E.L., Tolun, A and Petterwon, U., Two complementary atrandspecific termination tites for adenovirus DNA repliention, Cell, 9 (1976) 259-268.

Winmacke, E.L., Adenovirus DNA: structure and function of a novel replicon (review), Cell, 14 (1878) 761-773.

Wu, M., Roberts, R.J. and Davideon, N., Structure of the inverted terminal repetition of adenovirus type 2 DNA, J. Virol., 21 (1977) 766-777.

Zift, E.B. and Brans, R.M., Coincidence of the promoter and capped 5' terminus of RNA from the adenovirus 2 major late transeription unit, Call, 15 (1878) 1483-1475.

Communicated by A.J. van der Eb. 